\title{
Methylprednisolone or tirilazad mesylate administration after acute spinal cord injury: 1-year follow up
}

\section{Results of the third National Acute Spinal Cord Injury randomized controlled trial}

Michael B. Bracken, Ph.D., Mary Jo Shepard, M.P.H., Theodore R. Holford, Ph.D., Linda Leo-Summers, M.P.H., E. Francois Aldrich, M.D., Mahmood Fazl, M.D., Michael G. Fehlings, M.D., Ph.D., Daniel L. Herr, M.D., Patrick W. Hitchon, M.D., Lawrence F. Marshall, M.D., Russ P. Nockels, M.D., Valentine Pascale, R.Ph., Phanor L. Perot, Jr., M.D., Ph.D., Joseph Piepmeier, M.D., Volker K. H. Sonntag, M.D., Franklin Wagner, M.D., Jack E. Wilberger, M.D., H. Richard Winn, M.D., and Wise Young, M.D., Ph.D.

Departments of Epidemiology and Public Health, Neurology and Neurosurgery, Yale University School of Medicine, New Haven, Connecticut; University of Maryland, Baltimore, Maryland; Sunnybrook Medical Center, Toronto, Ontario, Canada; Washington Hospital Center, Washington, D.C.; University of Iowa Hospitals and Clinics, Iowa City, Iowa; University of California at San Diego, San Diego, California; Henry Ford Hospital, Detroit, Michigan; Medical University of South Carolina, Charleston, South Carolina; Barrow Neurological Institute, Phoenix, Arizona; University of California at Davis, Davis, California; Allegheny General Hospital, Pittsburgh, Pennsylvania; University of Washington-Harborview Medical Center, Seattle, Washington; and New York University-Bellevue Center, New York, New York

Object. A randomized double-blind clinical trial was conducted to compare neurological and functional recovery and morbidity and mortality rates 1 year after acute spinal cord injury in patients who had received a standard 24-hour methylprednisolone regimen (24MP) with those in whom an identical MP regimen had been delivered for 48 hours (48MP) or those who had received a 48-hour tirilazad mesylate (48TM) regimen.

Methods. Patients for whom treatment was initiated within 3 hours of injury showed equal neurological and functional recovery in all three treatment groups. Patients for whom treatment was delayed more than 3 hours experienced diminished motor function recovery in the $24 \mathrm{MP}$ group, but those in the 48MP group showed greater 1-year motor recovery (recovery scores of 13.7 and 19 , respectively, $p=0.053$ ).A greater percentage of patients improving three or more neurological grades was also observed in the 48MP group ( $\mathrm{p}=0.073$ ). In general, patients treated with 48TM recovered equally when compared with those who received 24MP treatments. A corresponding recovery in self care and sphincter control was seen but was not statistically significant. Mortality and morbidity rates at 1 year were similar in all groups. 
Conclusions. For patients in whom MP therapy is initiated within 3 hours of injury, 24-hour maintenance is appropriate. Patients starting therapy 3 to 8 hours after injury should be maintained on the regimen for 48 hours unless there are complicating medical factors.

Key Words * acute spinal cord injury * early treatment * methylprednisolone * tirilazad mesylate * randomized trial * pharmacological treatment

Pharmacological approaches for clinical improvement of neurological function in the treatment of acute spinal cord injury have been studied since 1977, primarily in three Phase III double-blind randomized clinical trials. In the first National Acute Spinal Cord Injury Study (NASCIS I) a 100-mg/24-hour regimen of methylprednisolone (MP) was compared with a 1000-mg/24-hour regimen, both administered over a 10-day period beginning within 48 hours after admittance to a spinal cord injury center in patients who had experienced traumatic spinal cord injury.[5,9] No difference in efficacy was observed between these treatments. In the second trial (NASCIS II) treatment with a bolus of MP at $30 \mathrm{mg} / \mathrm{kg}$ of body weight followed by a 23 -hour infusion of MP at $5.4 \mathrm{mg} / \mathrm{kg}$ or a $5.4-\mathrm{mg} / \mathrm{kg}$ bolus of naloxone followed by a 24-hour infusion at $4 \mathrm{mg} / \mathrm{kg}$ was compared with a placebo in patients randomized within 12 hours of injury. Patients treated with MP within 8 hours of injury experienced significantly improved neurological function over placebo-treated patients 6 weeks, 6 months,[7] and 1 year[8] postinjury.

In the third trial (NASCIS III) we examined whether 48-hour administration of MP (48MP) would provide improved neurological function compared with the 24-hour maintenance therapy (24MP). Posttraumatic lipid peroxidation, the secondary injury process hypothesized to be ameliorated by high-dose MP, $[3,18,27]$ is known to last well beyond 24 hours. $[18,29,30]$ In NASCIS III we also studied a 48-hour maintenance treatment with tirilazad mesylate (48TM), a potent lipid peroxidation inhibitor that was developed to treat central nervous system trauma with potentially fewer complications than anticipated from the high-dose 48MP regimen.[2,4,16,21,23,26]

Six-week and 6-month results of NASCIS III showed that patients treated within 3 hours of injury recovered equally in all three treatment groups. Among patients in whom the initiation of treatment was delayed for 3 to 8 hours after injury, the 24MP treatment showed a decline in efficacy, but this was not observed in the 48MP treatment. The neurological recovery rate for those treated with the 48TM regimen fell between that seen in the two MP regimens of the trial.[10]

In this paper we report the final 1-year follow-up results of NASCIS III for neurological and functional status and provide details on the mortality and morbidity statistics.

\section{CLINICAL MATERIAL AND METHODS}

\section{Patient Population}

The study methods have been detailed elsewhere[10] and are summarized here. Sixteen medical centers at which spinal cord injuries are treated collaborated in NASCIS III. The first patient was enrolled on December 18, 1991 and the last on September 30, 1995 (Appendix). Four hundred ninety-nine patients were randomized. Another 289 patients were clinically eligible but not enrolled, primarily because it was not possible to randomize them within the study's time limits (Fig. 1). 


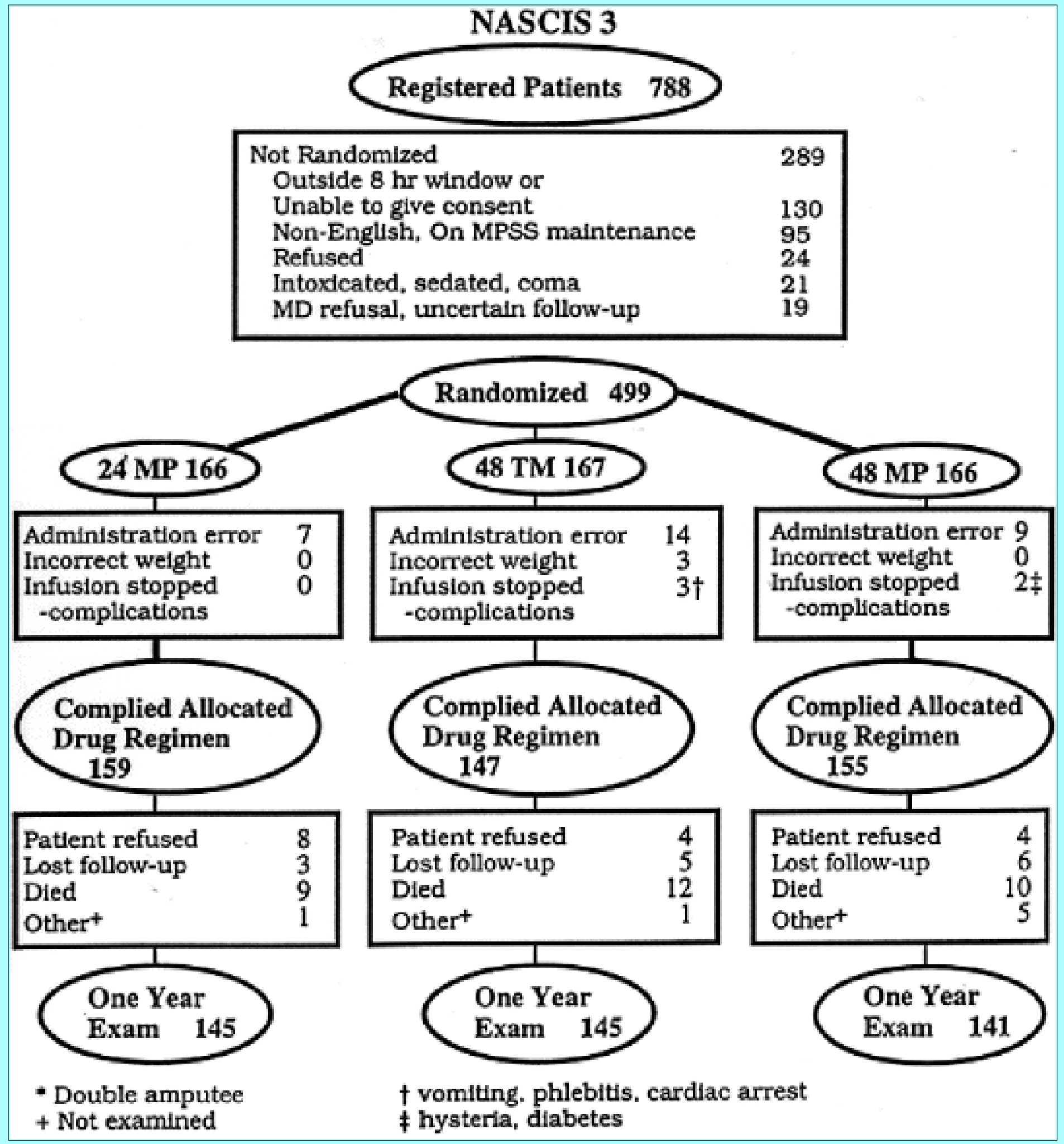

Fig. 1. Chart showing patient randomization, compliance, and follow up from the beginning of the study to the 1-year follow-up evaluation in NASCIS III. MPSS = methylprednisolone sodium succinate (or MP).

\section{Inclusion Criteria}

Attending physicians at the collaborating medical centers diagnosed spinal cord injury in a patient, determined that the individual met all criteria for randomization, and called the 24-hour line of the Yale New Haven Hospital Pharmacy for randomization. The Yale pharmacists ascertained that the patient was 
injured within the study's time limits and had given consent; then they calculated the drug dosages and imparted that information to a pharmacist at the randomizing center. All NASCIS study and medical personnel, except the principal investigator, were blinded to the drug protocol.

Patients were randomized to three groups: the 48MP group consisted of patients treated for 48 hours with MP infused at $5.4 \mathrm{mg} / \mathrm{kg} /$ hour; patients in the $24 \mathrm{MP}$ group received MP over a 24-hour period at the same dosage, with an additional 24 hours of placebo administration; patients in the 48TM group received $2.5 \mathrm{mg} / \mathrm{kg}$ TM given by intravenous bolus infusion for 15 to 20 minutes every 6 hours for 48 hours. All patients received a 30-mg/kg bolus dose of MP before randomization. The three treatment protocols were blocked in groups of nine patients within each center.

\section{Drug Preparation and Administration}

Bolus doses of MP were prepared from open stock supplies. The MP (or its placebo) for the NASCIS study was provided in kits containing 162 -g vials; doses were prepared following reconstitution with bacteriostatic water. Tirilazad or its placebo was provided in kits containing $16100-\mathrm{ml}$ vials that required no reconstitution. Patients were assigned to only one active treatment, whereas placebos for the alternate treatments were administered concurrently in separate masked infusions.

\section{Neurological and Functional Assessment}

Physicians at medical centers associated with NASCIS assessed patients' neurological function in the emergency room of that center at 72 hours ( \pm 1 hour), 6 weeks (42-49 days), 6 months (180-210 days), and 1 year (365-425 days) postinjury. Among patients surviving at 1 year, 16 refused to be examined, 14 were lost to follow up, and seven were not examined at 1 year for other reasons (Fig. 1). The NASCIS research nurses performed these follow-up examinations.

Motor Assessment. Fourteen muscle roots were measured bilaterally as follows: $0=$ no contraction; $1=$ flicker/trace of contraction; $2=$ active movement without antigravity; $3=$ active movement with antigravity; $4=$ active movement against resistance; and $5=$ normal. Scores ranged from 0 , which indicated no motor activity, to 70, which indicated normal motor function.

Sensory Assessment. Twenty-nine spinal cord segments were evaluated using pinprick and light touch and were scored as follows: $1=$ sensation absent, $2=$ dysfunctional (including hyperesthesia); and $3=$ normal. Responses ranged from 0 , which indicated no response in any segment, to a total of 87 , which indicated all segments were normal.

Functional Independence Measurement. At the time of their regularly scheduled follow-up neurological examinations, all patients underwent the functional independence measure (FIM) examination, which was administered by NASCIS research nurses.[25]

\section{Statistical Analysis}

All analyses were preplanned in the protocol. The primary endpoint was change in neurological function between the baseline and follow-up examinations. The trial was designed to detect motor change score differences of 5 or more with alpha set at 0.05 and beta at 0.2 , which required 150 patients in each group. Calculations were performed using the generalized linear model procedure in the statistical analysis system, and overall significance was tested using Type III sums of squares. We summarized results according to the time the bolus was received ( $3 / 43$ or $>3$ hours, the modal time from injury) and degree 
of neurological loss (complete or incomplete). For analysis of neurological scores we used data from the right side of the patient's body. In a few instances in which these data were unavailable the left side was used. Two-tailed tests of significance were used with a nominal probability value of 0.05 . To adjust for the effect of baseline differences on neurological change, for analysis of covariance we used the initial measure of function as a covariate. Adjusted means were used as the summary.

In a summary of patient survival we used the product-limit estimator of the survival curve, truncating follow-up at 375 days. The curves of the three treatment groups were compared using the log-rank test, calculated using LIFETEST software in SAS (Release 6.11; SAS Institute, Inc., Cary, NC, 1996).

The institutional review boards at all collaborating centers approved the full study protocol.

\section{RESULTS}

Of the 499 randomized patients, 431 , representing $92.1 \%$ of surviving patients, were evaluated at their 1-year follow up (Fig. 1). The demographic characteristics of the study population have been described previously[10] and were similar across the three treatment groups. However, baseline neurological scores differed, and patients treated with TM were more severely injured than patients in either MP group. This failure of randomization required that analyses of all follow-up examinations be corrected for baseline status.

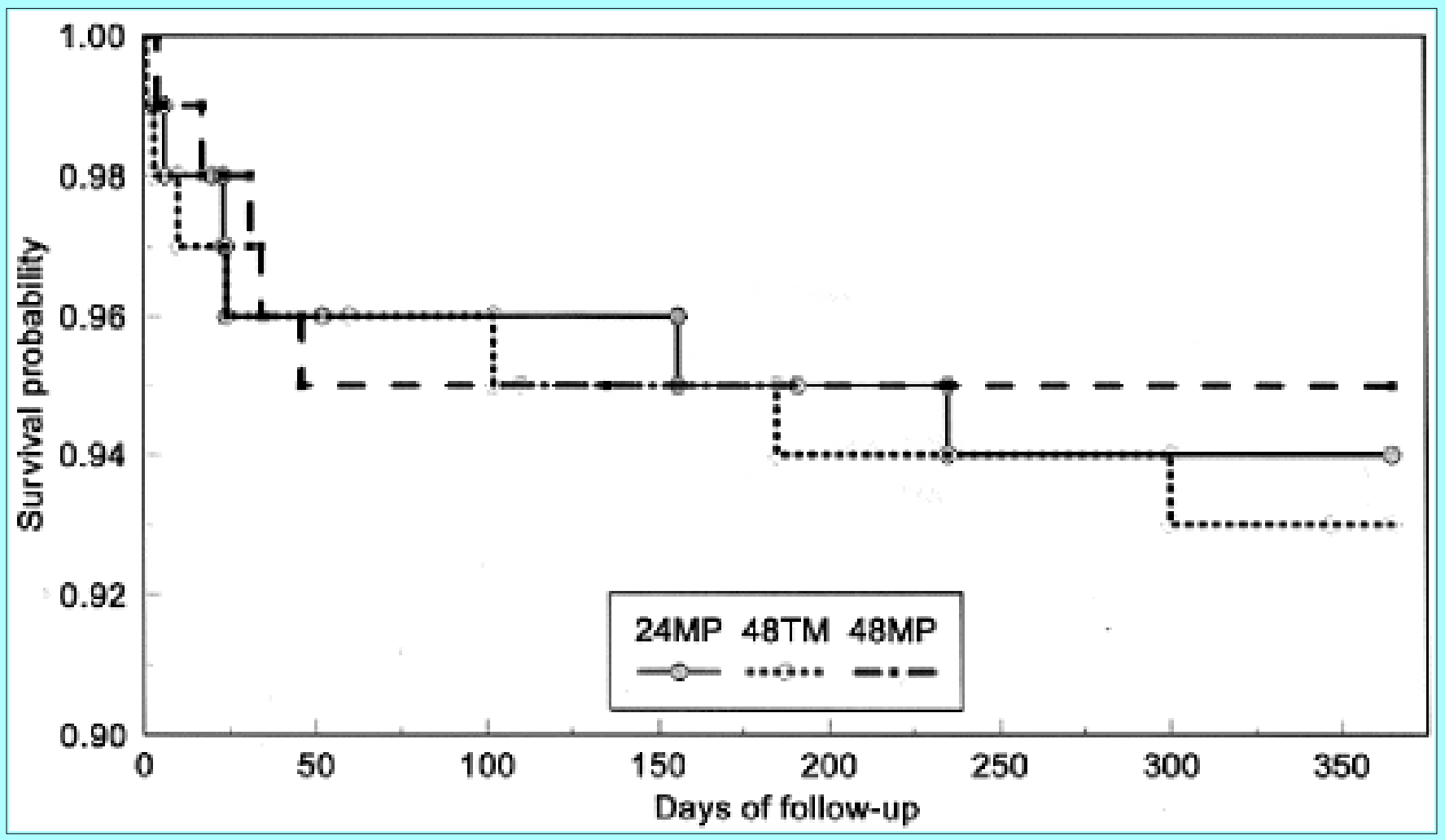

Fig. 2. Graph showing survival probability for patients in each treatment group 1 year after acute spinal cord injury (log-rank test $=0.44, \mathrm{~d} f=2, \mathrm{p}=0.8$ ).

The survival status was known for all patients. Figure 2 shows the survival rates for all three treatments, which ranged from 92.8 to $94.6 \%$ among the three treatment groups at 1 year $(\log$-rank test $=0.44, \mathrm{~d} f=$ $2, \mathrm{p}=0.8$ ). Table 1 shows the primary causes of death. More deaths resulted from pneumonia, respiratory distress syndrome (RDS), and respiratory failure in the 48TM and 48MP groups, a difference that may not be due to chance (24MP compared with $48 \mathrm{MP}, \mathrm{p}=0.056$ ). There was no meaningful distribution for 
the other primary causes of death.

\begin{tabular}{|c|c|c|c|}
\hline \multicolumn{4}{|c|}{$\begin{array}{c}\text { TABLE } 1 \\
\text { PRIMMRY CAUSES OF DEATHS OCCURRING IN THE 1ST VEAR POSTN.JRY BV } \\
\text { TREATMENT GROUP }\end{array}$} \\
\hline \multirow[b]{2}{*}{ Cause of Death } & \multicolumn{3}{|c|}{ Treatment Group } \\
\hline & $24 \mathrm{kWP}$ & $48 \mathrm{TM}$ & $48 \mathrm{NP}$ \\
\hline $\begin{array}{l}\text { sepsis, septic shock } \\
\text { pulmonary emboli } \\
\text { cardiopulmonary arrest } \\
\text { peritoneal hemopneumothorax } \\
\text { pneum onia, RDS, respiratory failure } \\
\text { renal \& multisystem failure } \\
\text { suicide, endotracheal tube removal } \\
\text { necro tizing enterooolitis } \\
\text { total deaths } \\
\text { randomized patients }\end{array}$ & $\begin{array}{r}1 \\
2 \\
3 \\
0 \\
1 \\
1 \\
0 \\
1 \\
9 \\
166\end{array}$ & $\begin{array}{r}0 \\
0 \\
3 \\
2 \\
4 \\
1 \\
2 \\
0 \\
12 \\
167\end{array}$ & $\begin{array}{r}1 \\
0 \\
3 \\
0 \\
6 \\
0 \\
0 \\
0 \\
10 \\
166\end{array}$ \\
\hline
\end{tabular}

\section{Neurological Function at 1 Year}

Table 2 shows results of the intent-to-treat analysis for motor function, pinprick, and sensation on light touch according to the three drug protocols. Overall, patients treated with 48MP attained better motor recovery than those given 24MP but this difference was quite modest $(p=0.232)$. Patients treated longer than 3 hours postinjury (but within 8 hours because of eligibility criteria) showed a diminished return of motor function in the 24MP group (a change score of 13.7), which was not seen in the 48MP group (change score 19, $\mathrm{p}=0.053$ ). Patients treated within 3 hours showed essentially the same motor recovery in all three drug protocols. Patients treated after 3 hours with $48 \mathrm{TM}$ recovered motor function to a similar extent to those receiving 24MP. These patterns of recovery were less evident for the sensory parameters, which generally showed a smaller effect of the treatment protocols on neurological recovery. 


\begin{tabular}{|c|c|c|c|}
\hline $\begin{array}{l}\text { TA } \\
\text { INTENT-TO-TREAT ANALVSS SH } \\
\text { NEUROLOGICAL FUNCTION SCO } \\
\text { AND BV COMPLETENESS }\end{array}$ & $\begin{array}{l}\text { LE } 2 \\
\text { NG ADJ } \\
\text { LOSE IN }\end{array}$ & $\begin{array}{l}\text { ISTED MEAN CH } \\
\text { AFTER INURV } \\
\text { MERGENCY RO }\end{array}$ & $\begin{array}{l}\text { JGES IN } \\
\text { VERALL } \\
\text { t }^{\star}\end{array}$ \\
\hline & & Treatmert Gr & \\
\hline Neurdogical Function & $24 \mathrm{kP}+$ & 48TM & $48 \mathrm{WP}$ \\
\hline al/patiens & & & \\
\hline $\begin{array}{l}\text { motor function } \\
\text { treatment initiation }\end{array}$ & 15.4 & $15.3(0.939)$ & $17.8(0.232)$ \\
\hline$=3 \mathrm{hrs}$ & 17.2 & $17.2(0.980)$ & $16.4(0.792)$ \\
\hline$>3 \mathrm{hrs}$ & 13.7 & $12.6(0.702)$ & $19.0(0.053)$ \\
\hline $\begin{array}{l}\text { pinprick sensation } \\
\text { treatment initiation }\end{array}$ & 10.0 & $8.3(0.226)$ & $10.4(0.795)$ \\
\hline$=3 \mathrm{hrs}$ & 10.9 & $9.3(0.426)$ & $10.2(0.723)$ \\
\hline$>3 \mathrm{hrs}$ & 9.2 & $6.9(0.263)$ & $10.6(0.494)$ \\
\hline light touch sensation & 9.6 & $8.7(0.542)$ & $10.6(0.518)$ \\
\hline $\begin{array}{l}\text { veaument inla } \\
=3 \text { hrs }\end{array}$ & 9.0 & & \\
\hline$>3$ hrs & 10.3 & $7.1(0.143)$ & $9.6(0.739)$ \\
\hline plegit patiens w/total sensarylass & & & \\
\hline motor function & 3.2 & $3.0(0.917)$ & $6.2(0.170)$ \\
\hline pinprick sensation & 1.2 & $1.3(0.952)$ & $3.8(0.156)$ \\
\hline light touch sensation & 1.0 & $2.0(0.601)$ & $3.8(0.136)$ \\
\hline incam dese patiens w/ lariable sens & ryos & & \\
\hline motor function & 27.1 & $27.9(0.695)$ & $30.5(0.110)$ \\
\hline pinprick sensation & 17.5 & $15.8(0.340)$ & $17.9(0.821)$ \\
\hline light touch sensation & 17.2 & $15.8(0.447)$ & $18.0(0.651)$ \\
\hline $\begin{array}{l}\text { "Adjusted for neurological function } \\
\text { variance. Num bers in parentheses in } \\
\text { son groups. } \\
\text { † Reference group. }\end{array}$ & emerg & $\begin{array}{l}\text { y room usin } \\
\text { ability values }\end{array}$ & $\begin{array}{l}\text { alysis of co- } \\
\text { the com pari- }\end{array}$ \\
\hline
\end{tabular}

Table 2 also shows recovery among patients in whom complete or incomplete neurological loss was diagnosed in the emergency room. In both groups of patients, those treated with 48MP regained more motor function than those treated with $24 \mathrm{MP}(\mathrm{p}=0.17$ and $\mathrm{p}=0.11$, respectively). These differences were smaller for the sensory measures. As expected, overall recovery was much less pronounced in those in whom complete neurological injuries were diagnosed at the time they were in the emergency room (data not shown). Among patients with either complete or incomplete injuries, those in whom treatment was initiated after 3 hours improved more in motor function with 48MP than with 24MP; respectively, complete scores for patients with injuries were 6.3 for 48MP compared with 1.5 for $24 \mathrm{MP}(\mathrm{p}=0.144)$ and for patients with incomplete injuries, scores were 30.1 compared with $26.3(\mathrm{p}=0.185)$.

Figure 1 shows that $38(7.6 \%)$ of the 499 randomized patients were noncompliant with their allocated drug regimen. Because these patients would not be expected to show maximal benefit from the study drug protocols, they were excluded from a replication of the foregoing analyses limited to compliant patients. All of the associations reported earlier were strengthened in the analysis of compliant patients (Table 3). 
TABLE 3

COMPLIERS ANALYSS SHOWNG ADUSTED MEAN CHANGES IN

NEUROLOGICAL FUNCTION SCORES 1 YEAR AFTER IN.URV OYERALL AND BV COMPLETENESS OF LOSS IN EMERGENCY ROOM*

\begin{tabular}{|c|c|c|c|}
\hline \multirow[b]{2}{*}{ Neurdogical Function } & \multicolumn{3}{|c|}{ Treatment Group } \\
\hline & 24MP† & $48 \mathrm{TM}$ & $48 \mathrm{NP}$ \\
\hline \multicolumn{4}{|l|}{ allpatients. } \\
\hline \multicolumn{3}{|l|}{ treatment initiation } & $18.0(0.168)$ \\
\hline$=3 \mathrm{hrs}$ & 17.2 & $17.7(0.867)$ & $16.5(0.823)$ \\
\hline$>3 \mathrm{hrs}$ & 13.3 & $13.0(0.924)$ & $19.4(0.032)$ \\
\hline \multicolumn{4}{|l|}{ treatment initiation } \\
\hline \pm 3 hrs & 10.6 & $9.6(0.617)$ & $9.9(0.743)$ \\
\hline$>3 \mathrm{hrs}$ & 8.9 & $7.1(0.417)$ & $10.1(0.538)$ \\
\hline \multicolumn{4}{|l|}{ light touch sensation } \\
\hline$\leq 3 \mathrm{hrs}$ & 8.6 & $9.9(0.545)$ & $11.2(0.237)$ \\
\hline$>3 \mathrm{hrs}$ & 10.0 & $7.3(0.227)$ & $9.5(0.798)$ \\
\hline \multicolumn{4}{|c|}{ glegic patiens $w /$ total sensary/ass } \\
\hline motor function & 3.0 & $2.9(0.961)$ & $6.6(0.100)$ \\
\hline pinprick sensation & 0.6 & $1.5(0.617)$ & $3.7(0.089)$ \\
\hline light touch sensation & 0.5 & $2.3(0.361)$ & $3.9(0.084)$ \\
\hline \multicolumn{4}{|c|}{ incam olete patiens w/ wriabe sensary foss } \\
\hline motor function & 27.1 & $28.4(0.555)$ & $31.4(0.054)$ \\
\hline pinprick sensation & 17.6 & $16.0(0.359)$ & $17.8(0.907)$ \\
\hline light touch sensation & 17.1 & $15.7(0.470)$ & $17.9(0.688)$ \\
\hline \multicolumn{4}{|c|}{$\begin{array}{l}\text { "Adjusted for neurological function in emergency room using anal ysis of co- } \\
\text { variance. Num bers in parentheses indicate probability values for the compari- } \\
\text { son group. } \\
\text { † Reference group. }\end{array}$} \\
\hline
\end{tabular}

Improvement in motor function increased from 13.3 to 19.4, respectively, in patients treated with 24MP and 48MP in whom initiation of treatment was delayed $(\mathrm{p}=0.032)$. Among patients with complete injuries, the overall improvement in motor function was 3 to 6.6 in $24 \mathrm{MP}$ compared with $48 \mathrm{MP}$ ( $\mathrm{p}=$ 0.100 ) and among patients with incomplete injuries, the respective motor change scores were 27.1 and $31.4(\mathrm{p}=0.054)$. Patients in whom complete injuries were diagnosed while they were in the emergency room and who received delayed treatment had motor change scores of 0.6 and 6.6 for the $24 \mathrm{MP}$ compared with the 48MP regimen $(\mathrm{p}=0.07)$. Scores in patients with incomplete injuries were 26.3 and 30.6 for the two regimens, respectively $(\mathrm{p}=0.143)$. In all of the neurological analyses the patients in the 48TM group recovered to a level between those in the two MP groups.

We examined whether improved neurological recovery was sufficient to reassign patients from one of the four motor dysfunctional categories to a higher functional group; for example, from quadriplegic to paraplegic, quadriparetic, paraparetic, or normal. Using intent-to-treat analysis, $56.1 \%$ of patients treated with 48MP improved at least one grade compared with $47.2 \%$ of patients treated with $24 \mathrm{MP}$ (relative improvement $1.19,95 \%$ confidence interval $[\mathrm{CI}] 0.92-1.53, \mathrm{p}=0.178)$. Improvement rates for patients in these two groups who underwent delayed treatment, in whom regimens were initiated 3 to 8 hours postinjury, were $58.2 \%$ and $43.8 \%$, respectively (relative improvement $=1.33,95 \%$ CI $0.93-1.90, \mathrm{p}=$ 0.111 ). Among patients who received delayed treatment with 48MP, 29.8\% recovered three or more grades compared with $17.5 \%$ of patients in whom delayed treatment with $24 \mathrm{MP}$ was administered (relative improvement $=1.75,95 \%$ CI $0.93-3.31, \mathrm{p}=0.073$ ). Corresponding improvements for patients 
receiving TM fell between those observed for the two MP-treated groups.

\section{One-Year FIM Scores}

Table 4 presents the 1-year FIM scores in the intent-to-treat and compliers analysis. For almost all the FIMs, total and component scores, patients treated with 48MP experienced better functional recovery than those receiving 24MP. However, these differences were not large, and the strongest association was for self care in the compliers analysis $(\mathrm{p}=0.085)$. Higher total and component FIM scores were seen in patients treated with 48MP who had either complete or incomplete injuries, with stronger associations in patients treated after 3 hours and for those in the compliers analysis (data not shown). However, none of these associations reached nominal statistical significance.

\begin{tabular}{|c|c|c|c|c|c|c|}
\hline \multicolumn{7}{|c|}{ TABLE 4} \\
\hline \multirow[b]{2}{*}{$\mathrm{FlM}$} & \multicolumn{3}{|c|}{ Int ent- o-Treat } & \multicolumn{3}{|c|}{ Compliers } \\
\hline & $24 \mathrm{MPT}$ & $48 \mathrm{TM}$ & $48 \mathrm{MP}$ & 24kP† & 48TM & $48 \mathrm{WP}$ \\
\hline $\begin{array}{l}\text { total FIM } \\
\text { self care } \\
\text { sphincter control } \\
\text { motility } \\
\text { locomotion } \\
\text { communication } \\
\text { social cognition }\end{array}$ & $\begin{array}{r}102.7 \\
32.5 \\
10.0 \\
15.6 \\
9.9 \\
13.9 \\
20.8\end{array}$ & $\begin{array}{r}103.2(0.844) \\
33.0(0.650) \\
10.0(0.838) \\
15.9(0.638) \\
9.7(0.596) \\
13.9(0.299) \\
20.6(0.214)\end{array}$ & $\begin{array}{r}105.3(0.289) \\
34.2(0.151) \\
10.5(0.196) \\
16.1(0.394) \\
10.0(0.801) \\
13.9(0.446) \\
20.5(0.109)\end{array}$ & $\begin{array}{r}102.5 \\
32.5 \\
9.9 \\
15.5 \\
9.8 \\
13.9 \\
20.8\end{array}$ & $\begin{array}{r}103.3(0.745) \\
33.1(0.638) \\
10.1(0.599) \\
15.9(0.583) \\
9.7(0.708) \\
13.9(0.253) \\
20.6(0.284)\end{array}$ & $\begin{array}{r}106.0(0.158) \\
34.6(0.085) \\
10.5(0.124) \\
16.3(0.227) \\
10.0(0.707) \\
13.9(0.921) \\
20.6(0.255)\end{array}$ \\
\hline $\begin{array}{l}\text { "Adjusted for } \\
\text { parentheses indi } \\
\dagger \text { Referenoe gr }\end{array}$ & & $m$ & on score by & & & \\
\hline
\end{tabular}

\section{Complications of Treatment}

Table 5 lists new complications reported for the first time at 6 months and 1 year postinjury. Complications that manifested before 6 weeks were reported in a previous publication.[10] Overall, there was little difference in the frequency of adverse events among the three treatment groups.

Mild-to-moderate urinary tract infections occurred most commonly $(66 \%)$ in the 48TM group $(\mathrm{p}=0.01)$, whereas severe urinary tract infections were somewhat more common in patients treated with 48MP (3.3\%, $\mathrm{p}=0.20)$. Mild-to-moderate pneumonia occurred most frequently after treatment with 48TM $(7.3 \%, p=0.12)$ but for severe pneumonia there was essentially no difference among treatment groups. 


\begin{tabular}{|c|c|c|c|c|}
\hline $\begin{array}{l}\text { COMBINED 6-MONTH AI } \\
\text { SEVERTV }\end{array}$ & $\begin{array}{l}\text { TABL } \\
\text { 1-VEAR } \\
\text { PROTO }\end{array}$ & PLLATI & V DEG & \\
\hline & & & & \\
\hline Complication \& Severity† & 24kP & 48TM & $48 \mathrm{MP}$ & p Yalue \\
\hline urinary tract infection & & & & \\
\hline mild to moderate & 53.1 & 66.0 & 49.0 & 0.01 \\
\hline severe & 0.8 & 1.3 & 3.3 & 0.20 \\
\hline decubiti & & & & \\
\hline mild to moderate & 13.8 & 16.0 & 13.4 & 0.79 \\
\hline severe & 3.4 & 6.7 & 6.0 & 0.43 \\
\hline other infection & & & & \\
\hline mild to moderate & 4.1 & 4.7 & 4.0 & 0.96 \\
\hline Severe & 0.7 & 0.7 & 0.7 & 1.00 \\
\hline phletitis & & & & \\
\hline mild to moderate & 0.7 & 0.7 & 0 & 0.60 \\
\hline severe & 0 & 0 & 0 & 1.00 \\
\hline incision, pin, \& halo infection & & & & \\
\hline mild to moderate & 1.4 & 0.7 & 0.7 & 0.76 \\
\hline severe & 0 & 0 & 0 & 1.00 \\
\hline sepsis & & & & \\
\hline mild to moderate & 0 & 0 & 1.3 & 0.14 \\
\hline severe & 0 & 0.7 & 1.3 & 0.37 \\
\hline adult RDS & & & & \\
\hline mild to moderate & 0 & 0.7 & 0 & 0.37 \\
\hline severe & 0.7 & 2.0 & 0 & 0.18 \\
\hline atelectasis & & & & \\
\hline mild to moderate & 1.4 & 2.0 & 0.7 & 0.61 \\
\hline Severe & 0.7 & 0.7 & 0 & 0.60 \\
\hline other respiratory failure & & & & \\
\hline mild to moderate & 1.4 & 1.3 & 0 & 0.36 \\
\hline $\begin{array}{r}\text { Severe } \\
\text { meumonia. }\end{array}$ & 0 & 1.3 & 0.7 & 0.38 \\
\hline mild to moderate & 2.8 & 7.3 & & \\
\hline severe & 1.4 & 0.7 & 1.4 & 0.81 \\
\hline Gl hemorrhage & & & & \\
\hline mild to moderate & 0 & 0 & 0 & 1.00 \\
\hline Severe & 0 & 0 & 0 & 1.00 \\
\hline throm bophletitis & & & & \\
\hline mild to moderate & 2.1 & 2.7 & 2.7 & 0.93 \\
\hline severe & 1.4 & 1.3 & 0.7 & 0.81 \\
\hline $\begin{array}{l}\text { "Oocurence first reported a } \\
\text { Values ewcept for those in the } \\
\text { e wents. A btre vation: Gl = gas } \\
\dagger \text { Mild = did not interfere wi th } \\
\text { ference; se vere = significant ir } \\
\ddagger \text { Number of respondents wh } \\
149 \text { patients in the } 24 \mathrm{MP} \text {, } 48 \\
\text { numbers mere } 145,145 \text {, and }\end{array}$ & $\begin{array}{l}\text { ither th } \\
\text { t colum } \\
\text { intestin } \\
\text { tient's }\end{array}$ & $\begin{array}{l}\text { nonth o } \\
\text { oresent } \\
\text { functio } \\
\text { o patien } \\
\text { juated } \\
P \text { group }\end{array}$ & $\begin{array}{l}\text { ear foll } \\
\text { eroent } \\
\text { oderate } \\
\text { sual fur } \\
\text { nonths } \\
\text { specti }\end{array}$ & $\begin{array}{l}\text { Ap review } \\
\text { of adverse } \\
\text { ome inter- } \\
\text { o. } 145,150 \text {, } \\
\text { One-year }\end{array}$ \\
\hline
\end{tabular}

\section{DISCUSSION}

\section{Neurological Recovery:}

The 1-year follow-up results of NASCIS III essentially confirm those observed at the 6-week and 6-month follow up.[10] The overall NASCIS III motor recovery scores are shown in Fig. 3. Patients in all three treatment groups showed further neurological and functional recovery at 1 year. The rate of recovery was slower between 6 months and 1 year compared with the period between 6 weeks and 6 
months, which was also observed in the two previous NASCIS trials.[5,7-9] Patients in whom treatment was initiated within 3 hours after injury recovered equally well in all three drug protocols. Among patients whose treatment was initiated longer than 3 hours after injury, those receiving 48MP showed greater recovery in motor function $(p=0.053)$, overall functional independence $(p=0.289)$, and self care $(\mathrm{p}=0.151)$ than the respective $24 \mathrm{MP}$ group. Improvements in recovery among patients who received delayed treatment with 48MP were observed in those with complete $(\mathrm{p}=0.17)$ and incomplete neurological injuries $(\mathrm{p}=0.11)$ at the time of trauma. All of these relative improvements at 1 year were modest, and in the intent-to-treat analysis did not meet nominal levels of statistical significance $(\mathrm{p}>$ $0.05)$ which, for example, were observed at 6 weeks $(p=0.04)$ and 6 months $(p=0.01)$ in the motor function improvement scores in those treated after 3 hours.[10]

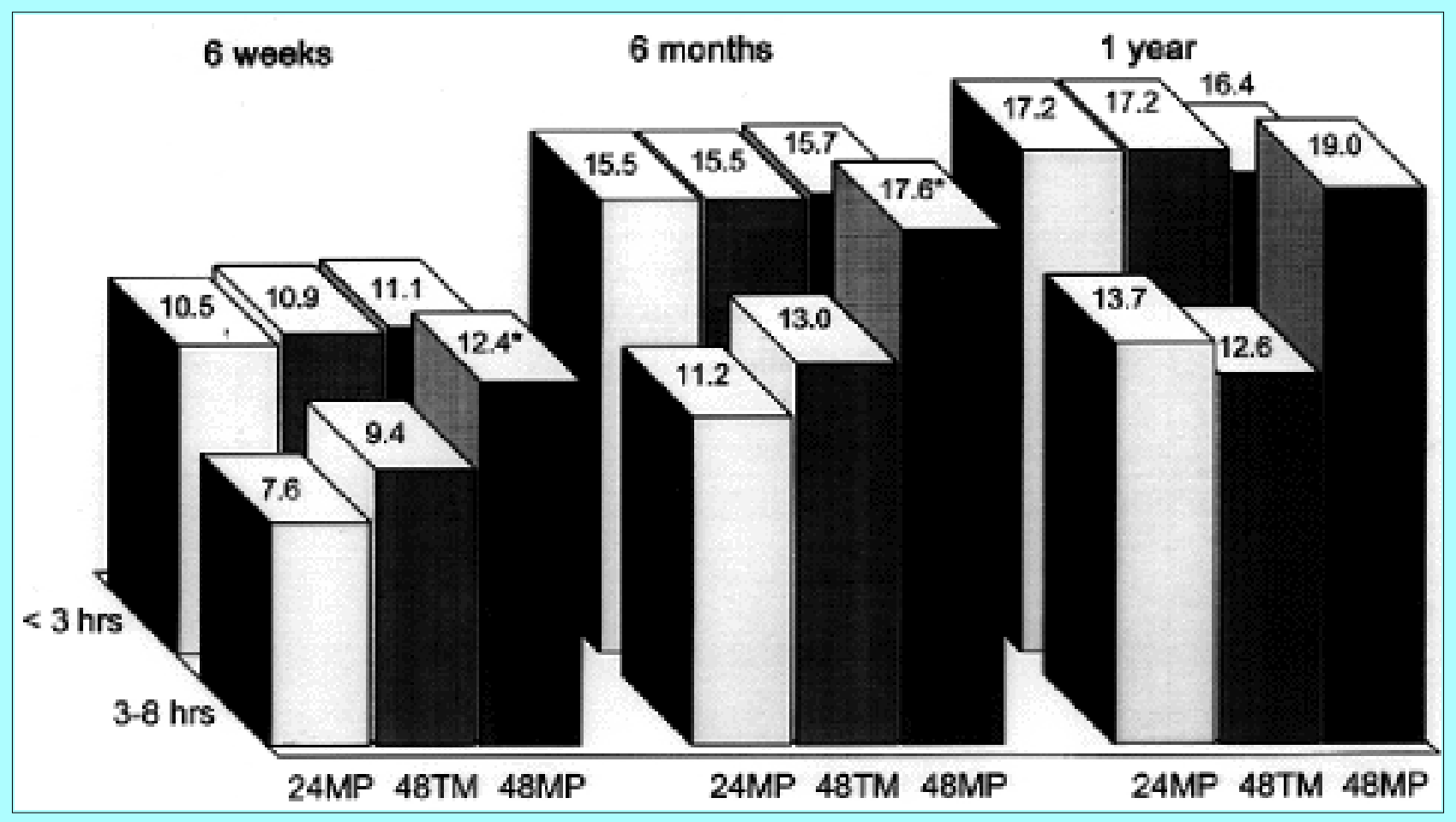

Fig. 3. Bar graph showing motor improvement score at 6 weeks, 6 months, and 1 year after injury by time from accident to bolus dose. Intent-to-treat analysis was adjusted for emergency room motor score. * $\mathrm{p}<0.05$.

In the compliers analysis, in which 38 patients who did not receive their study drug treatment according to protocol were excluded, treatment effects were larger, as would be expected if the drug were having a real effect. However, the intent-to-treat analysis reflected neurological and functional improvements that are more likely to be observed in the vicissitudes of normal clinical practice, when protocols may not always be followed precisely.

\section{Functional Recovery}

When we examined whether the clinical improvement seen in the 3- to 8-hour delayed treatment group led to improvement in their neurological grade, those given 48MP were 1.75 times more likely to recover three or more grades (95\% CI 0.93-3.31, $\mathrm{p}=0.073$ ), a finding that must be associated with functional recovery and that correlates with the relative improvement in the FIM self-care score. It is not surprising that the total FIM scores did not show a larger change because two components: 1) communication, which is composed of comprehension and expression; and 2) social cognition, which is a combination of social interaction, problem solving, and memory, are not generally affected by spinal cord injury. This is 
reflected by the almost maximal scores (14 and 21, respectively) at all time periods. On the other hand, the FIM scores for self care (eating, grooming, bathing, dressing upper and lower body, and toileting) were reduced in all patients by approximately $22 \%$ from the maximum score of 42 ; and sphincter control (bladder and bowel management) by approximately 33\% from its maximum score of 14.[1] These two components appeared to be most influenced by the 48MP protocol, perhaps reflecting greater upper body improvement, but the differences were not large and were even smaller for the mobility and locomotion components.

In the NASCIS II trial functional status was not evaluated, and it is useful to contrast the effect of 24MP against placebo on neurological recovery in that trial with the NASCIS III results, given their almost identical study protocols. The NASCIS II data at 1 year showed improvements of 5.2 in motor function scores for 24MP compared with placebo in all patients $(\mathrm{p}=0.03)$ and $6.6(\mathrm{p}=0.014)$ in compliers. [8] In NASCIS III, motor improvement scores of 5 in the 48MP group 6-month intent-to-treat analysis $(\mathrm{p}=$ $0.07)$ were associated with increases in total FIM scores $(\mathrm{p}=0.08)$, self care $(\mathrm{p}=0.03)$, and sphincter control $(\mathrm{p}=0.01)$.[10] It seems highly likely, therefore, that had FIM been assessed in NASCIS II, similar improvements in 24MP compared with placebo FIM scores would have been observed.

\section{Possible Mechanisms}

Why might the efficacy of 24MP decline in patients treated longer than 3 hours after injury? This effect could not be studied in NASCIS II because, with overall 12-hour eligibility criteria, too few patients were treated within 3 hours to provide reliable estimates of effect. The most likely secondary injury process, which high-dose MP is thought to affect, is lipid peroxidation and hydrolytic destruction of neuronal and microvascular membranes, $[3,14,17,18,27]$ a process that continues for several days after injury.[18,29,30] When secondary posttraumatic spinal cord injury is increased because of delayed treatment, it is likely to be more difficult to slow the postinjury cascade of neurodestructive events. Delayed reactions are also manifested as hemoglobin oxidation in subarachnoid clots after subarachnoid hemorrhage.[30]

Single-bolus dosing does not attenuate posttraumatic spinal ischemia,[11,12,22] and in experiments in which 48MP dosing was used[13] it was not compared with 24-hour regimens. With even longer delays in treatment to longer than 8 hours in NASCIS II, we observed reduced recovery with 24MP treatment compared with placebo.[6] This may be because the secondary injury cascade becomes so advanced that it is refractory to 24MP treatment. After 8 hours the beneficial effects of MP are lost and its negative role in inhibiting immune cell activity[28] and axonal sprouting[19] may dominate.

Tirilazad mesylate continues to have equivalent efficacy to $24 \mathrm{MP}$ treatment at 1 year, as was observed at 6 weeks and 6 months.[10] Tirilazad is a potent inhibitor of lipid peroxidation[15,20,21] and its lack of equivalence with 48MP has three possible explanations. The benefit of 48MP may be derived from its antiinflammatory actions, $[18,27]$ although dose levels of MP that inhibit lipid peroxidation do not show antiinflammatory actions.[24,31] Second, the level of TM used in this study may have been too low or not given for long enough to achieve an optimal effect. Third, despite randomization, patients in the 48TM group were more severely injured than those in the MP groups. We may have been unable to correct fully for this difference statistically in the follow-up analyses.

All three protocols were associated with similar complication rates as assessed at 6 months and 1 year postinjury. Mild-to-moderate urinary tract infections were most common after 48TM (66\%) and least common after 48MP treatment (47\%), whereas severe infection was most common after 48MP but only 
occurred in $3.3 \%$ of patients. For some complications, the more immediate ones reported at 6 weeks may be more relevant for drug effects.[10] Overall survival rates at 1 year did not differ in a meaningful way among the three drug protocols and ranged from 92.8 to $94.6 \%$. This is a high overall survival rate that may be due in part to the exclusion of patients with gunshot wounds and head injuries.

The 1-year results of NASCIS III lend additional support to the extended clinical use of high-dose MP in patients whose initial therapy cannot be started until more than 3 hours after injury, but before 8 hours when high-dose MP may have deleterious effects.[6] Because approximately half of all patients with spinal injuries are admitted in the 3- to 8-hour window, according to the NASCIS III data, this recommendation should be of benefit to a substantial number of patients. However, the significant increases in severe pneumonia seen at 6 weeks after 48MP treatment,[10] and the observation of possible increased mortality rates caused by pneumonia, RDS, or respiratory failure, call for caution in managing patients with complicating medical factors who are being treated with 48MP and avoiding its unnecessary use in patients who could be treated for 24 hours.

\section{Appendix}

National Acute Spinal Cord Injury Study

NASCIS Coordinating Center: Yale University School of Medicine

Principal Investigator: Michael B. Bracken, Ph.D., M.P.H.

Project Coordinator: Mary Jo Shepard, M.P.H.

Senior Biostatistician: Theodore R. Holford, Ph.D.

Software Systems Programmer: Linda Leo-Summers, M.P.H.

Director of Investigational Drugs: Valentine Pascale, R.Ph.

Pharmacy Technician: Glenda Leake

Monitoring Committee

National Institute of Neurological Disorders and Stroke

Michael D. Walker, M.D. (chair); Mary Ellen Cheung, Ph.D.

Johns Hopkins University

Donlin M. Long, M.D.

University of Michigan

William Barsan, M.D.

Baylor College of Medicine

Charles Contant, Ph.D.

Boston University

Edward L. Spatz, M.D.

Collaborating Centers

Yale University School of Medicine (12 patients)

Joseph Piepmeier, M.D.; Elaine Flynn, R.N.; Debbie Webb, R.N.; and Linda DeGutis, Dr.P.H., R.N. 
Wise Young, M.D.; Donna Whitam, R.N.; Carey Erickson; and Michael Whitehouse, R.N.

Medical University of South Carolina (45 patients)

Phanor L. Perot, Jr., M.D., Ph.D.; Bonnie Muntz-Pope, R.N., C.N.R.N.; and Peggy Auberry, R.N.

University of California, San Diego (23 patients)

Lawrence F. Marshall, M.D.; Theresa Gautile, R.N.; Shermaine Frei, R.N.; and Lesley Overton, R.N.

University of California, Davis (49 patients)

Franklin C. Wagner, M.D.; Karen Smith, R.N., C.N.R.N.; and Barry Emrick, P.A.C

University of California, San Francisco (24 patients)

Randall Chesnut, M.D.; Lawrence H. Pitts, M.D.; Sue Damron, R.N.; Leslie Ferguson-Dietz, R.N., C.C.R.N., C.N.R.N.; Theresa Zecca, R.N.; Joan Little, R.N.; and Greg Lambdin, B.S.N.

Barrow Neurological Institute (68 patients)

Volker K. H. Sonntag, M.D.; Janine B. Drabier, R.N., M.S.; and Jean E. Lopez, R.N., M.S.N.

University of Iowa Hospitals and Clinics (37 patients)

Patrick W. Hitchon, M.D.; Gatana Stoner, R.N.; Sandy Tomas, R.N.; Susan Piper, R.N.; and Karen VanDenBosch

University of Washington-Harborview Medical Center (65 patients)

H. Richard Winn, M.D.; M. Sean Grady, M.D.; Pam Thomson, R.N.; Mary Foley, R.N.; Dolors Jones, R.N.; and Heather Bybee, R.N.

Allegheny General Hospital (76 patients)

Jack E. Wilberger, M.D.; Diane Cantella, R.N.; and Jeff Bost, P.A.

Toronto Western Hospital (11 patients)

Charles Tator, M.D.; Michael G. Fehlings, M.D.; and Sharon Hossain, R.N.

Sunnybrook Medical Centre (33 patients)

Mahmood Fazl, M.D.; Chen Li, M.D.; and Katie Weaver, R.N.

University of Maryland (28 patients)

Howard M. Eisenberg, M.D.; E. Francois Aldrich, M.D.; Charlene Aldrich, R.N.; and Cindy Minkin, R.N.

Henry Ford Hospital (2 patients)

Russ P. Nockels, M.D., and Melissa Azuara, R.N.

Washington Hospital Center (19 patients)

Daniel L. Herr, M.D.; Chris Kemmerle-Pierre, R.N.; Peggy Iarola, R.N.; Pamela Shumate, R.N.; and Alyssa Leimberger, R.N.

(Collaborating Center changes: Russ P. Nockels, M.D., formerly at University of California, San Francisco; Howard M. Eisenberg, M.D., and Charlene Aldrich, R.N., formerly at University of Texas Medical Branch [2 patients]).

\section{Disclosure}

Pharmacia and Upjohn, Inc. funded additional tests and monitored data quality at participating centers to 
meet regulatory requirements of the Food and Drug Administration, and they also provided study drugs and placebos. Dr. Bracken has served as an occasional paid consultant to Pharmacia and Upjohn.

\section{References}

1. American Spinal Injury Association: Standards for Neurological and Functional Classification of Spinal Cord Injury, rev ed. Chicago, Ill: American Spinal Injury Association, 1992

2. Anderson DK, Braughler JM, Hall ED, et al: Effects of treatment with U-74006F on neurological outcome following experimental spinal cord injury. J Neurosurg 69:562-567, 1988

3. Anderson DK, Dugan LL, Means ED, et al: Methylprednisolone and membrane properties of primary cultures of mouse spinal cord. Brain Res 637:119-125, 1994

4. Anderson DK, Hall ED, Braughler JM, et al: Effect of delayed administration of U74006F (tirilazad mesylate) on recovery of locomotor function after experimental spinal cord injury. $\mathbf{J}$ Neurotrauma 8:187-192, 1991

5. Bracken MB, Collins WF, Freeman DF, et al: Efficacy of methylprednisolone in acute spinal cord injury. JAMA 251:45-52, 1984

6. Bracken MB, Holford TR: Effect of timing of methylprednisolone or naloxone administration on recovery of segmental and long-tract neurological function in NASCIS 2. J Neurosurg 79:500-507, 1993

7. Bracken MB, Shepard MJ, Collins WF, et al: A randomized controlled trial of methylprednisolone or naloxone in the treatment of acute spinal cord injury. Results of the second National Acute Spinal Cord Injury Study. N Engl J Med 322:1405-1411, 1990

8. Bracken MB, Shepard MJ, Collins WF Jr, et al: Methylprednisolone or naloxone treatment after acute spinal cord injury: 1-year follow-up data. Results of the second National Acute Spinal Cord Injury Study. J Neurosurg 76:23-31, 1992

9. Bracken MB, Shepard MJ, Hellenbrand KG, et al: Methylprednisolone and neurological function 1 year after spinal cord injury. Results of the National Acute Spinal Cord Injury Study. J Neurosurg 63:704-713, 1985

10. Bracken MB, Shepard MJ, Holford TR, et al: Administration of methylprednisolone for 24 or 48 hours or tirilazad mesylate for 48 hours in the treatment of acute spinal cord injury. Results of the third National Acute Spinal Cord Injury randomized controlled trial. JAMA 277:1597-1604, 1997

11. Braughler JM, Hall ED: Effects of multi-dose methylprednisolone sodium succinate administration on injured cat spinal cord neurofilament degradation and energy metabolism. J Neurosurg 61:290-295, 1984

12. Braughler JM, Hall ED: Lactate and pyruvate metabolism in the injured cat spinal cord before and after a single large intravenous dose of methylprednisolone. J Neurosurg 59:256-261, 1983

13. Braughler JM, Hall ED, Means ED, et al: Evaluation of an intensive methylprednisolone sodium succinate dosing regimen in experimental spinal cord injury. J Neurosurg 67:102-105, 1987 
14. Constantini S, Young W: The effects of methylprednisolone and the ganglioside GM1 on acute spinal cord injury in rats. J Neurosurg 80:97-111, 1994

15. Demopoulos HB, Flamm ES, Pietronigro DD, et al: The free radical pathology and the microcirculation in the major central nervous system disorders. Acta Physiol Scand Suppl 492:91-119, 1980

16. Hall ED: Effects of the 21-aminosteroid U74006F on posttraumatic spinal cord ischemia in cats. J Neurosurg 68:462-465, 1988

17. Hall ED: Neuroprotective actions of glucocorticoid and nonglucocorticoid steroids in acute neuronal injury. Cell Mol Neurobiol 13:415-432, 1993

18. Hall ED: The neuroprotective pharmacology of methylprednisolone. J Neurosurg 76:13-22, 1992

19. Hall ED: Steroids and neuronal destruction or stabilization, in Chadwick D, Widdows K (eds):

Steroids and Neuronal Activity. Ciba Foundation Symposium, Vol 153. Chichester, England: Wiley \& Sons, 1990, pp 206-214

20. Hall ED, Braughler JM: Free radicals in CNS injury. Res Publ Assoc Res Nerv Ment Dis 71:81-105, 1993

21. Hall ED, McCall JM, Means ED: Therapeutic potential of the lazaroids (21-aminosteroids) in acute central nervous system trauma, ischemia and subarachnoid hemorrhage. Adv Pharmacol 28:221-268, 1994

22. Hall ED, Wolf DL, Braughler JM: Effects of a single large dose of methylprednisolone sodium succinate on experimental posttraumatic spinal cord ischemia. Dose-response and time-action analysis. $\mathbf{J}$ Neurosurg 61:124-130, 1984

23. Hall ED, Yonkers PA, Horan KL, et al: Correlation between attenuation of posttraumatic spinal cord ischemia and preservation of tissue vitamin $\mathrm{E}$ by the 21-aminosteroid $\mathrm{U} 74006 \mathrm{~F}$ : evidence for an in vivo antioxidant mechanism. J Neurotrauma 6:169-176, 1989

24. Hall ED, Yonkers PA, Taylor BA, et al: Lack of effect of postinjury treatment with methylprednisolone or tirilazad mesylate on the increase in eicosanoid levels in the acutely injured cat spinal cord. J Neurotrauma 12:245-256, 1995

25. Hamilton BB, Granger CV, Sherwin FS, et al: A uniform national data system for medical rehabilitation, in Fuhrer MJ (ed): Rehabilitation Outcomes: Analysis and Measurement. Baltimore: Paul H Brookes, 1987, pp 137-147

26. Holtz A, Gerdin B: Efficacy of 21-aminosteroid U-74006F in improving neurological recovery after spinal cord injury in rats. Neurol Res 14:49-52, 1992

27. Hsu CY, Dimitrijevic MR: Methylprednisolone in spinal cord injury: the possible mechanism of action. J Neurotrauma 7:115-119, 1990

28. Kelly TA: The role of the immune system in central nervous system regeneration (theoretical considerations). Med Hypotheses 26:13-15, 1988 
29. Sadrzadeh SMH, Anderson DK, Panter SS, et al: Hemoglobin potentiates central nervous system damage. J Clin Invest 79:662-664, 1987

30. Sano K, Asano T, Tanishima T, et al: Lipid peroxidation as a cause of cerebral vasospasm. Neurol Res 2:253-272, 1980

31. Xu J, Qu ZX, Hogan EL, et al: Protective effect of methylprednisolone on vascular injury in rat spinal cord injury. J Neurotrauma 9:245-253, 1992

Manuscript received January 29, 1998.

Accepted in final form June 2, 1998.

Supported by Grant No. NS-15078 from the National Institute of Neurological Disorders and Stroke.

Address reprint requests to: Michael B. Bracken, Ph.D., Department of Epidemiology and Public Health, Yale University School of Medicine, 60 College Street, P.O. Box 208034, New Haven, Connecticut 06520-8034. 